\title{
FITOSSANIDADE
}

\section{COMPARAÇÕES SAZONAIS DO EFEITO DA XYLELLA FASTIDIOSA EM CULTIVARES DE CAFEEIRO(1)}

\author{
RACHEL BENETTI QUEIROZ-VOLTAN ${ }^{(2)}$; LUCIANE PEROSIN CABRAL ${ }^{(3)}$; \\ OSVALDO PARADELA FILHO ${ }^{(4)}$
}

\begin{abstract}
RESUMO
Há muitos anos, o cafeeiro vem apresentando problemas de atrofia e seca dos ramos, atribuídos a um esgotamento nutricional devido às altas taxas de produção. Entretanto, hoje sabe-se que esse problema é causado pela presença da bactéria Xylella fastidiosa Wells et al. cujos sintomas estão relacionados a fatores de estresse. Embora essa bactéria tenha sido muito estudada nos Estados Unidos, devido aos danos causados à videira, pouco se conhece sobre a relação patógeno-hospedeiro-vetor nas diferentes culturas. O objetivo deste trabalho foi o de avaliar a obstrução de elementos de vaso do xilema nas diferentes partes da planta, em ramos com e sem sintomas externos de infecção, de cultivares de cafeeiro (porta-enxertados ou pé-franco), em duas épocas do ano, a fim de verificar o efeito da bactéria na estrutura da planta e na sua nutrição. Foi utilizado um experimento instalado em 1986, em Garça (SP), sendo as amostras retiradas em 2000. Para o estudo anatômico foram obtidas amostras em dois períodos: abril/maio (estação seca) e novembro/dezembro (estação chuvosa) e para as análises foliar e edáfica foram retiradas amostras em abril. A proporção de obstrução de elementos de vaso do xilema devido ao efeito ocasionado pela bactéria foi maior na estação seca, no período de estresse hídrico, do que na estação chuvosa. O órgão que apresentou uma proporção maior de obstrução de elementos de vaso foi o caule, seguido do pecíolo, limbo e raiz. Não houve diferença significativa na proporção de elementos de vaso obstruídos entre os tratamentos nos dois períodos do ano; também, não houve diferença significativa na composição nutricional foliar nas condições do estudo, porém as amostras retiradas dos ramos com sintoma de infecção, de alguns tratamentos, apresentaram menores concentrações de alguns elementos químicos em relação àquelas amostras retiradas de ramos sem sintoma da presença da bactéria.
\end{abstract}

Palavras-chave: cafeeiro, condução, nutrientes, obstrução, sazonalidade, xilema.

\section{ABSTRACT \\ SEASONAL COMPARACTIONS OF XYLELLA FASTIDIOSA EFFECT IN COFFEE CULTIVARS}

Historically, coffee plants showing atrophy and scorch branch were attributed to nutritional disorders due to successive high yields. The bacteria XylelLa fastidiosa Wells et al. is currently the most reported pathogen related with the problem and the symptoms are associated with stress. Although the bacteria has been well studied in the United States particularly in grape, few is known about the pathogenhost-vector relationship. The present studies were carried out with coffee plants (grafted or not grafted) aiming to evaluate xylem vessels obstruction in various plant parts, including branches with and without

$\left({ }^{1}\right)$ Com recursos complementares do Consórcio Brasileiro de Pesquisa e Desenvolvimento do Café. Recebido para publicação em 12 de dezembro de 2003 e aceito em 24 de junho de 2004.

$\left(^{2}\right)$ Núcleo de Pesquisa e Desenvolvimento do Jardim Botânico/Centro Experimental Central/IAC, Caixa Postal 28, 13001-970 Campinas (SP). E-mail: rachelqv@iac.sp.gov.br

$\left(^{3}\right)$ Bolsista do Consórcio Brasileiro de Pesquisa e Desenvolvimento do Café.

$\left({ }^{4}\right)$ Centro de Pesquisa e Desenvolvimento de Fitossanidade/IAC. 
external symptom expression. Two seasons of plantation were assessed in a year and the parameters evaluated were: nutritional and structural bacteria as affected by water supply to the bacteria. The experiments were installed in 1986 in the coffee region of Garça, São Paulo State. The samples, for anatomic studies, were taken in two period of the year 2000: April - May (water stress) e November - December (rainy periods). Leaf and soil samples for analyses were taken in April 2000. The highest proportion of xylem vessels obstruction due to the bacteria was noticed during the water stress period as compared with the rainy season. There were not significant differences on bacterium coffee effect between the two sampling periods. The bacterium presence did not show difference among nutritional leaf composition, however the symptomatic branches of some genetic material showed smaller concentration of some nutrients when compared with assymptomatic branches.

Key words: Coffee plants, conduction, nutrients, obliteration, seasonality, xylem.

\section{INTRODUÇÃO}

A bactéria Xylella fastidiosa Wells et al. vem causando prejuízos às culturas economicamente importantes desde 1892, quando foi detectada na Califórnia em espécimes de videira. Diversas culturas de regiões climáticas tropicais e subtropicais como a alfafa (GoHEen et al., 1973), pessegueiro (HopKins et al., 1973; NYLAND et al., 1973), amendoeira (MiRCETICH et al., 1976), ameixeira (HopKINS, 1989), citros (CHAGAS et al., 1992), dentre outros hospedeiros de menor interesse (Hopkins E AdLerz, 1988), também apresentaram problemas com essa bactéria. No cafeeiro, foi descrita por PARADELA et al. (1995).

No Brasil, essa bactéria tem causado prejuízos até de $35 \%$ na cultura de citros, enquanto na cafeicultura, embora não tenha sido quantificada sua significância econômica, registrou-se, em São José do Rio Preto (SP), redução de $30 \%$ na produção em algumas plantações (Prato, 2000).

A grande maioria dos hospedeiros naturais dessa bactéria ocorre na Flórida e pertence a 28 famílias botânicas, incluindo mono e dicotiledôneas, sendo muitas hospedeiras assintomáticas (HoPKINs e Adlerz, 1988). A X. fastidiosa é transmitida por cigarrinhas das famílias Cicadellidae (subfamília Cicadellinae) e Cercopidae, que se alimentam dos ramos e folhas (Hopkins, 1989; LOPES, 1996; PAIVA et al., 1996).

A causa principal da doença tem sido atribuída a uma disfunção no sistema condutor de água, relacionada com a oclusão de elementos de vaso do xilema por "gomas", tiloses ou células bacterianas (Esau, 1948; Mircetich et al., 1976; Mollenhauer e HopkINS, 1976). Existem, porém, divergências na literatura se essas oclusões seriam suficientes para causar um estresse hídrico (Мircetich et al., 1976; French e Stassi, 1978; HopKINS, 1981). Outras duas hipóteses para a origem dos sintomas da doença são a da fitotoxina (Mircetich et al., 1976; LeE et al., 1982) e a do desbalanço de reguladores de crescimento (French e Stassi, 1978).
Segundo Paradela Filho et al. $(1997,1999)$, há muitos anos o cafeeiro vem apresentando sintomas de infecção pela $X$. fastidiosa, os quais, entretanto, eram atribuídos a um esgotamento nutricional devido a altas produções.

Esses autores consideram que a bactéria foi disseminada de plantas de cafeeiro para as de laranjeira no Brasil devido à presença da clorose variegada de citros em lavouras que sucederam à cultura cafeeira e, pela similaridade dos vetores transmissores dessa bactéria.

O efeito dessa bactéria na anatomia da planta foi descrito por QueIroz-Voltan et al. (1998), em que se discutiu a forte evidência de uma relação entre $X$. fastidiosa e senescência, associada a fatores de estresse.

Os principais sintomas dessa doença em cafeeiro são entrenós mais curtos, tornando as folhas mais próximas entre si e conferindo-lhes um arranjo em roseta; diminuição no comprimento dos pecíolos e na área foliar; senescência precoce das folhas mais maduras, resultando em um ramo com pequeno número de folhas no seu ápice. Devido ao encurtamento dos pedicelos e dos entrenós, as flores e frutos ficam agrupados e ocorre, também, redução em seu tamanho (PARAdela Filho et al. 1997; QueIrozVoltan et al., 1998).

Xylella fastidiosa tem sido muito estudada nos Estados Unidos, porém pouco ainda se conhece sobre essa bactéria e sua relação com as plantas hospedeiras e seus vetores.

O objetivo deste trabalho foi avaliar, em cultivares de cafeeiro porta-enxertados ou não (péfranco), a obstrução (total e parcial) de elementos de vaso do xilema na planta: folha (nervura principal e pecíolo), caule e raiz, com e sem sintomas visuais de infecção por X. fastidiosa, em duas épocas do ano, caracterizadas por diferentes condições pluviais, a fim de se verificar a possível relação da disponibilidade de água no solo com o efeito da bactéria e os teores de nutrientes na estrutura da planta. 


\section{MATERIAL E MÉTODOS}

Foi utilizado um experimento de cafeeiro enxertado, instalado em 1986 na Fazenda da Mata, município de Garça, Estado de São Paulo. O delineamento utilizado foi o de blocos ao acaso, com dez tratamentos e cinco repetições, em espaçamento de 3,5 × 2,0 m e as parcelas de quatro covas, cada uma com duas plantas. Como porta-enxerto, utilizaram-se duas progênies de Coffea canephora Pierre ex A. Froehner - Apoatã IAC 2258 e IAC 2286 - e uma de C. congensis A. Froehner - IAC Bangelan coleção 5. Como enxerto, empregaram-se duas cultivares de $C$. arabica L., Catuaí Vermelho IAC H 2077-2-5-81 e Mundo Novo IAC 515-20. Todas as progênies utilizadas como portaenxerto eram oriundas de plantas matrizes selecionadas pelo Centro de Análise e Pesquisa Tecnológica do Agronegócio do Café/IAC/APTA, em áreas infestadas por nematóides. Efetuaram-se, também, auto-enxertias no Catuaí e no Mundo Novo, considerando-se as plantas não- enxertadas dessas cultivares como testemunha.

A cultura do cafeeiro foi desenvolvida em condições ideais de adubação, calagem e tratos culturais recomendados para a cultura (RAIJ et al., 1997). A adubação com nitrato de amônio foi realizada em 10/11/1999 e as adubações NPK 25-00-20, aplicadas em 15/12/1999, 20/01/2000 e 18/2/2000.

A análise foliar foi realizada em 100 amostras de plantas, retiradas dos dez tratamentos (plantas enxertadas ou pé-franco). De cada tratamento, foram retirados cinco ramos com e cinco sem sintoma de infecção pela X. fastidiosa de cada parcela. Desses ramos, retiraram-se quatro folhas por planta do $3 .^{\circ}$ nó de cada ramo posicionados na altura média da planta. Após três lavagens em água destilada, as folhas foram secas em estufa a $60{ }^{\circ} \mathrm{C}$. Os teores de macro e micronutrientes foram determinados segundo Bataglia et al. (1983). O efeito dos tratamentos foi avaliado pelo teste $F$ e as médias, de variâncias homogêneas, foram comparadas pelo teste de Tukey a $5 \%$.

As amostras de solo foram retiradas em 20 pontos, em profundidades de 0 a $20 \mathrm{~cm}$, com o auxílio de um trado, distando 20 a $50 \mathrm{~cm}$ do eixo principal da planta. A amostra de $0,5 \mathrm{~kg}$ foi retirada dessas subamostras.

A amostra foliar e a de solo foram retiradas em abril de 2000 para análise no laboratório do Centro de Pesquisa e Desenvolvimento de Solos e Recursos Ambientais do Instituto Agronômico.

O estudo anatômico foi realizado em 2000, em duas épocas do ano: a primeira caracterizada por uma estação seca, em abril e maio, e a segunda, correspondente ao período chuvoso, em novembro e dezembro. As amostras aleatórias consistiram de cinco plantas de cada tratamento, sendo uma planta representativa de cada parcela. De cada planta, retiraram-se ramos aparentemente sadios, outros com sintomas de infecção e raízes laterais a $0,5 \mathrm{~m}$ do eixo principal da planta. De cada uma das partes foram utilizados cinco segmentos de $0,5 \mathrm{~cm}$ de comprimento de caule, de raiz e do pecíolo, além de $0,25 \mathrm{~cm}^{2}$ da região da nervura principal, na porção mediana da lâmina de folhas adultas de cada planta amostrada. Os segmentos do pecíolo foram retirados na porção mediana e para as amostras de folhas com sintoma, utilizou-se todo o comprimento do pecíolo; os segmentos do caule foram retirados da região mediana de ramos correspondente entre o $6 .^{\circ}$ ou $7 .^{\circ}$ nó do eixo principal e o das raízes da região compreendida entre 5 e $15 \mathrm{~cm}$ do seu ápice.

Os segmentos foram fixados em solução etílica (50\%) de formaldeído-ácido acético (F.A.A. 50\%) (JohANSEn, 1940) e, posteriormente, as porções de interesse de pecíolo e limbo, incluídas em parafina e seccionadas transversalmente em micrótomo de rotação; as de caule e raiz foram seccionadas em criostato a $-28^{\circ} \mathrm{C}$.

A espessura das secções foi de $12 \mu \mathrm{m}$ e a coloração utilizada, a de safranina-alcian blue, modificada por GABRIELli (1992). A obstrução de elementos de vaso do xilema foi estudada nos diferentes órgãos, totalizando 150 observações por amostra. A proporção foi estimada considerando-se o número de elementos de vasos que se apresentavam total ou parcialmente obstruídos por goma em relação ao número total de elementos de vaso por campo de área conhecida. Uma vez que a proporção de elementos de vaso obstruídos apresentava uma distribuição binomial, foram estimadas as respectivas médias e o desvio-padrão dos tratamentos os quais foram comparados através de seus intervalos de confiança a 5\% de significância (SOKAL e RoHLF, 1981).

\section{RESULTADOS E DISCUSSÃO}

No período seco (maio-junho), houve uma proporção maior de elementos de vaso obstruídos do que no período chuvoso (novembro-dezembro) (Tabelas 1 e 2). Embora o período chuvoso em 2000 tenha sido caracterizado por baixa pluviosidade, a porcentagem média de elementos de vaso obstruídos na planta, no segundo período, foi de $1 \%$, bem menor do que no período seco que variou de $3 \%$ a $7 \%$ nos diferentes órgãos. 
Tabela 1. Média, desvio-padrão e intervalo de confiança das estimativas de obstrução de elementos de vaso do xilema em diferentes partes do cafeeiro na região de Garça (SP), no período seco (abril-maio), considerando toda a planta ( $\mathrm{n}=300$ para cada limbo foliar, pecíolo e caule e $\mathrm{n}=150$ para a raiz)

\begin{tabular}{|c|c|c|c|}
\hline Tratamento & Média & Desvio-padrão & Intervalo de confiança \\
\hline & \multicolumn{3}{|c|}{ Limbo foliar (nervura principal) } \\
\hline Catuaí/Apoatã & 0,0324 & 0,0544 & $0,0123 \leq \Pi \leq 0,0524)$ \\
\hline Catuaí/ Bangelan & 0,0446 & 0,0681 & $(0,0212 \leq \Pi \leq 0,0680)$ \\
\hline Catuaí/IAC 2286 & 0,0630 & 0,0794 & $(0,0355 \leq \Pi \leq 0,0905)$ \\
\hline Mundo Novo/Apoatã & 0,0197 & 0,0395 & $(0,0040 \leq \Pi \leq 0,0354)$ \\
\hline Mundo Novo/Bangelan & 0,0216 & 0,0459 & $(0,0051 \leq \Pi \leq 0,0380)$ \\
\hline Mundo Novo/IAC 2286 & 0,0280 & 0,0557 & $(0,0093 \leq \Pi \leq 0,0466)$ \\
\hline Catuaí/ Catuaí & 0,0189 & 0,0423 & $(0,0035 \leq \Pi \leq 0,0342)$ \\
\hline Mundo Novo/ Mundo Novo & 0,0349 & 0,0509 & $(0,0141 \leq \Pi \leq 0,0556)$ \\
\hline Mundo Novo (testemunha) & 0,0199 & 0,0393 & $(0,0041 \leq \Pi \leq 0,0357)$ \\
\hline Catuaí (testemunha) & 0,0264 & 0,0443 & $(0,0082 \leq \Pi \leq 0,0445)$ \\
\hline \multirow[t]{2}{*}{ Média total } & 0,0309 & 0,0550 & \\
\hline & \multicolumn{3}{|c|}{ Pecíolo } \\
\hline Catuaí/Apoatã & 0,0492 & 0,0819 & $(0,0247 \leq \Pi \leq 0,0737)$ \\
\hline Catuaí/ Bangelan & 0,0670 & 0,0849 & $(0,0387 \leq \Pi \leq 0,0953)$ \\
\hline Catuaí/IAC 2286 & 0,0817 & 0,0885 & $(0,0507 \leq \Pi \leq 0,1127)$ \\
\hline Mundo Novo/Apoatã & 0,0291 & 0,0516 & $(0,0101 \leq \Pi \leq 0,0481)$ \\
\hline Mundo Novo/Bangelan & 0,0738 & 0,0962 & $(0,0442 \leq \Pi \leq 0,1034)$ \\
\hline Mundo Novo/IAC 2286 & 0,0692 & 0,1156 & $(0,0405 \leq \Pi \leq 0,0980)$ \\
\hline Catuaí/ Catuaí & 0,0534 & 0,1056 & $(0,0280 \leq \Pi \leq 0,0789)$ \\
\hline Mundo Novo/ Mundo Novo & 0,0440 & 0,0691 & $(0,0208 \leq \Pi \leq 0,0672)$ \\
\hline Mundo Novo (testemunha) & 0,0426 & 0,0765 & $(0,0197 \leq \Pi \leq 0,0654)$ \\
\hline Catuaí (testemunha) & 0,0518 & 0,0682 & $(0,0267 \leq \Pi \leq 0,0768)$ \\
\hline \multirow[t]{2}{*}{ Média total } & 0,0562 & 0,0870 & \\
\hline & \multicolumn{3}{|c|}{ Caule } \\
\hline Catuaí/Apoatã & 0,0691 & 0,0867 & $(0,0404 \leq \Pi \leq 0,0978)$ \\
\hline Catuaí/ Bangelan & 0,0722 & 0,0852 & $(0,0429 \leq \Pi \leq 0,1015)$ \\
\hline Catuaí/IAC 2286 & 0,0801 & 0,0978 & $(0,0494 \leq \Pi \leq 0,1108)$ \\
\hline Mundo Novo/Apoatã & 0,0473 & 0,0867 & $(0,0233 \leq \Pi \leq 0,0714)$ \\
\hline Mundo Novo/Bangelan & 0,0883 & 0,1275 & $(0,0562 \leq \Pi \leq 0,1205)$ \\
\hline Mundo Novo/IAC 2286 & 0,0903 & 0,1182 & $(0,0579 \leq \Pi \leq 0,1227)$ \\
\hline Catuaí/ Catuaí & 0,0436 & 0,0757 & $(0,0205 \leq \Pi \leq 0,0667)$ \\
\hline Mundo Novo/ Mundo Novo & 0,0520 & 0,0849 & $(0,0268 \leq \Pi \leq 0,0672)$ \\
\hline Mundo Novo (testemunha) & 0,0498 & 0,0795 & $(0,0251 \leq \Pi \leq 0,0654)$ \\
\hline Catuaí (testemunha) & 0,0710 & 0,0918 & $(0,0419 \leq \Pi \leq 0,0768)$ \\
\hline \multirow[t]{2}{*}{ Média total } & 0,0664 & 0,0960 & \\
\hline & \multicolumn{3}{|c|}{ Raiz } \\
\hline Catuaí/Apoatã & 0,0760 & 0,1129 & $(0,0336 \leq \Pi \leq 0,1184)$ \\
\hline Catuaí/ Bangelan & 0,0527 & 0,0868 & $(0,0170 \leq \Pi \leq 0,0885)$ \\
\hline Catuaí/IAC 2286 & 0,0563 & 0,0845 & $(0,0194 \leq \Pi \leq 0,0931)$ \\
\hline Mundo Novo/Apoatã & 0,0280 & 0,0583 & $(0,0016 \leq \Pi \leq 0,0543)$ \\
\hline Mundo Novo/Bangelan & 0,0148 & 0,0326 & $(-0,0045 \leq \Pi \leq 0,0341)$ \\
\hline Mundo Novo/IAC 2286 & 0,0279 & 0,0553 & $(0,0015 \leq \Pi \leq 0,0542)$ \\
\hline Catuaí/ Catuaí & 0,0302 & 0,0633 & $(0,0028 \leq \Pi \leq 0,0576)$ \\
\hline Mundo Novo/ Mundo Novo & 0,0194 & 0,0402 & $(-0,0027 \leq \Pi \leq 0,0415)$ \\
\hline Mundo Novo (testemunha) & 0,0330 & 0,0697 & $(0,0044 \leq \Pi \leq 0,0616)$ \\
\hline Catuaí (testemunha) & 0,0198 & 0,0642 & $(-0,0025 \leq \Pi \leq 0,0421)$ \\
\hline Média total & 0,0358 & 0,0726 & \\
\hline
\end{tabular}


Tabela 2. Médias, desvio-padrão e intervalos de confiança das estimativas de obstrução de vasos do xilema obtidas em diferentes partes do cafeeiro na região de Garça (SP), no período chuvoso (nov-dez), considerando toda a planta ( $\mathrm{n}=300$ para cada limbo foliar, pecíolo e caule e $\mathrm{n}=150$ para a raiz)

\begin{tabular}{|c|c|c|c|}
\hline Tratamento & Média & Desvio-padrão & Intervalo de confiança \\
\hline & \multicolumn{3}{|c|}{ Limbo foliar (nervura principal) } \\
\hline Catuaí/Apoatã & 0,0121 & 0,0304 & $(-0,0003 \leq \Pi \leq 0,0244)$ \\
\hline Catuaí/ Bangelan & 0,0133 & 0,0263 & $(0,0003 \leq \Pi \leq 0,0263)$ \\
\hline Catuaí/IAC 2286 & 0,0191 & 0,0398 & $(0,0036 \leq \Pi \leq 0,0345)$ \\
\hline Mundo Novo/Apoatã & 0,0120 & 0,0272 & $(-0,0003 \leq \Pi \leq 0,0243)$ \\
\hline Mundo Novo/Bangelan & 0,0138 & 0,0328 & $(0,0006 \leq \Pi \leq 0,0269)$ \\
\hline Mundo Novo/IAC 2286 & 0,0121 & 0,0279 & $(-0,0003 \leq \Pi \leq 0,0245)$ \\
\hline Catuaí/ Catuaí & 0,0077 & 0,0224 & $(-0,0022 \leq \Pi \leq 0,0175)$ \\
\hline Mundo Novo/ Mundo Novo & 0,0097 & 0,0258 & $(-0,0014 \leq \Pi \leq 0,0208)$ \\
\hline Mundo Novo (testemunha) & 0,0076 & 0,0257 & $(-0,0022 \leq \Pi \leq 0,0174)$ \\
\hline Catuaí (testemunha) & 0,0161 & 0,0342 & $(0,0019 \leq \Pi \leq 0,0305)$ \\
\hline \multirow[t]{2}{*}{ Média total } & 0,0123 & 0,0298 & \\
\hline & \multicolumn{3}{|c|}{ Pecíolo } \\
\hline Catuaí/Apoatã & 0,0168 & 0,0428 & $(0,0022 \leq \Pi \leq 0,0313)$ \\
\hline Catuaí/ Bangelan & 0,0180 & 0,0395 & $(0,0029 \leq \Pi \leq 0,0330)$ \\
\hline Catuaí/IAC 2286 & 0,0233 & 0,048 & $(0,0062 \leq \Pi \leq 0,0404)$ \\
\hline Mundo Novo/Apoatã & 0,0218 & 0,0609 & $(0,0053 \leq \Pi \leq 0,0384)$ \\
\hline Mundo Novo/Bangelan & 0,0108 & 0,0380 & $(-0,0009 \leq \Pi \leq 0,0225)$ \\
\hline Mundo Novo/IAC 2286 & 0,0201 & 0,0480 & $(0,0042 \leq \Pi \leq 0,0360)$ \\
\hline Catuaí/ Catuaí & 0,0210 & 0,0529 & $(0,0048 \leq \Pi \leq 0,0372)$ \\
\hline Mundo Novo/ Mundo Novo & 0,0157 & 0,0572 & $(0,0016 \leq \Pi \leq 0,0297)$ \\
\hline Mundo Novo (testemunha) & 0,0086 & 0,0370 & $(-0,0019 \leq \Pi \leq 0,0190)$ \\
\hline Catuaí (testemunha) & 0,0169 & 0,0420 & $(0,0023 \leq \Pi \leq 0,0315)$ \\
\hline \multirow[t]{2}{*}{ Média total } & 0,0173 & 0,0475 & \\
\hline & \multicolumn{3}{|c|}{ Caule } \\
\hline Catuaí/Apoatã & 0,0053 & 0,0199 & $(-0,0029 \leq \Pi \leq 0,0135)$ \\
\hline Catuaí/ Bangelan & 0,0124 & 0,0498 & $(-0,0001 \leq \Pi \leq 0,0249)$ \\
\hline Catuaí/IAC 2286 & 0,0109 & 0,0408 & $(-0,0008 \leq \Pi \leq 0,0227)$ \\
\hline Mundo Novo/Apoatã & 0,0055 & 0,0269 & $(-0,0029 \leq \Pi \leq 0,0139)$ \\
\hline Mundo Novo/Bangelan & 0,0091 & 0,0373 & $(-0,0017 \leq \Pi \leq 0,0198)$ \\
\hline Mundo Novo/IAC 2286 & 0,0131 & 0,0406 & $(0,0002 \leq \Pi \leq 0,0260)$ \\
\hline Catuaí/ Catuaí & 0,0157 & 0,0548 & $(0,0016 \leq \Pi \leq 0,0297)$ \\
\hline Mundo Novo/ Mundo Novo & 0,0159 & 0,0460 & $(0,0018 \leq \Pi \leq 0,0301)$ \\
\hline Mundo Novo (testemunha) & 0,0155 & 0,0515 & $(0,0015 \leq \Pi \leq 0,0294)$ \\
\hline Catuaí (testemunha) & 0,0123 & 0,0415 & $(-0,0002 \leq \Pi \leq 0,0248)$ \\
\hline \multirow[t]{2}{*}{ Média total } & 0,0116 & 0,0423 & \\
\hline & \multicolumn{3}{|c|}{ Raiz } \\
\hline Catuaí/Apoatã & 0,0035 & 0,0119 & $(-0,0060 \leq \Pi \leq 0,0130)$ \\
\hline Catuaí/ Bangelan & 0,0053 & 0,0241 & $(-0,0063 \leq \Pi \leq 0,0169)$ \\
\hline Catuaí/IAC 2286 & 0,0083 & 0,0298 & $(-0,0062 \leq \Pi \leq 0,0228)$ \\
\hline Mundo Novo/Apoatã & 0,0192 & 0,0392 & $(-0,0028 \leq \Pi \leq 0,0412)$ \\
\hline Mundo Novo/Bangelan & 0,0056 & 0,0192 & $(-0,0063 \leq \Pi \leq 0,0175)$ \\
\hline Mundo Novo/IAC 2286 & 0,0060 & 0,0171 & $(-0,0064 \leq \Pi \leq 0,0183)$ \\
\hline Catuaí/ Catuaí & 0,0077 & 0,0222 & $(-0,0063 \leq \Pi \leq 0,0217)$ \\
\hline Mundo Novo/ Mundo Novo & 0,0131 & 0,0359 & $(-0,0051 \leq \Pi \leq 0,0313)$ \\
\hline Mundo Novo (testemunha) & 0,0157 & 0,0401 & $(-0,0042 \leq \Pi \leq 0,0355)$ \\
\hline Catuaí (testemunha) & 0,0094 & 0,0244 & $(-0,0060 \leq \Pi \leq 0,0248)$ \\
\hline Média Total & 0,0094 & 0,0282 & \\
\hline
\end{tabular}


Mesmo a presença de pouca chuva resultou em proporção menor de obstrução de elementos de vaso do xilema, sugerindo que o déficit hídrico não deve ser o único fator determinante do sintoma de obstrução de elementos de vaso pela bactéria, mas que outro(s) fator(es) de estresse fisiológico ou ambiental provavelmente interage $(\mathrm{m})$ na resposta da planta.

$\mathrm{O}$ órgão que apresentou maior obstrução de elementos de vaso do xilema no período de seca foi o caule, seguido do pecíolo, limbo foliar e raiz. Entretanto, não houve diferença entre os tratamentos em nenhum dos órgãos amostrados, como pode ser observado através dos intervalos de confiança que se sobrepõem. Observou-se que, embora os intervalos sejam coincidentes, a cultivar Mundo Novo enxertada sobre a Apoatã tende a apresentar uma proporção menor de elementos de vaso obstruídos em todos os órgãos no período de seca (Tabelas 1, 3 e 4).

$\mathrm{Na}$ tabela 3, pode-se visualizar que, tanto no período de seca como no chuvoso, os órgãos dos ramos sem sintoma externo da $X$. fastidiosa apresentaram obstrução de elementos de vaso em proporções menores do que nos ramos com sintoma externo. No período de seca, as médias da proporção de obstrução dos vasos foram maiores do que no chuvoso, em ramos com e sem sintoma externo. Reforça-se a idéia que o estresse hídrico maximiza a obstrução de elementos de vaso do xilema, com aumento dos sintomas externos indesejáveis, tais como: diminuição de área foliar e arranjo das folhas apicais em roseta e senescência das demais folhas, frutos menores e densamente agrupados, diminuição no número de cloroplastos, ou seja, fatores que causam decréscimo no metabolismo fotossintético e, conseqüentemente, na produção.

Com o início da estação chuvosa, observouse a brotação de novos ramos, de menor número com o sintoma. Os ramos com os sintomas do período de seca, que apresentavam disposição das folhas apicais em roseta, secavam, sendo a nova aparência do cafezal atribuída aos ramos rebrotados e que voltavam na maioria das vezes a apresentar os sintomas externos da presença da bactéria, na estação seca do ano seguinte (2001).

$\mathrm{Na}$ tabela 4, observa-se que os intervalos de confiança entre os tratamentos se sobrepuseram nos ramos com e sem sintoma nas duas épocas do ano avaliadas.

Uma variação sazonal também ocorreu em videira, com alta concentração da bactéria no fim da primavera e início de verão e mais baixa no outono até o inverno, quando as folhas senesceram (HoPKINS, 1981; 1991 e HoPKINS e THOMPSON, 1984). Segundo tais autores, havia necrose marginal nas folhas quando a obstrução atingia $80 \%$ de obstrução dos vasos.
No pessegueiro (Prunus persica), segundo Evert e Mullinix (1983) havia um potencial hídrico menor durante o dia nos meses de outono nas folhas de árvores com média a alta concentração da bactéria quando comparado à primavera. Os sintomas externos do pessegueiro eram resultantes do estresse hídrico da árvore devido ao processo de transpiração. Nessa cultura, as bactérias invadiam novos elementos de vaso do xilema a cada ano. A variação sazonal em Citrus, como observado por HopKINs (1991) consistiu de um pico da bactéria no inverno, seguido de um decréscimo e, novamente, outro pico ocorrido no verão.

Diversos trabalhos realizados com diferentes culturas têm demonstrado que o aumento da concentração da bactéria está relacionado à maior intensidade do sintoma externo e, também, com o pico das populações dos vetores (HOPKINS, 1991; HOPKINS E Thompson, 1984; Fry e Milholland, 1990; Oliveira E VALLIM, 2002).

Os resultados da análise foliar (Tabelas 5 e 6) demonstraram que o estado nutricional das plantas estava dentro dos limites dos teores adequados de macro e micronutrientes da matéria seca, descritas para o cafeeiro por RAIJ et al. (1997). Não houve diferença entre os tratamentos amostrados na maioria dos macro e micronutrientes, quando se considerou a amostra total da planta (folhas de ramos com e sem sintoma de infecção) e os ramos com e sem sintoma de forma separada. A diferença foi significativa para o cálcio, que aumentou, e o manganês, que diminuiu nas plantas enxertadas. A variação da concentração desses macro e micronutrientes, parecem não estar diretamente relacionadas à infecção pela $X$. fastidiosa, mas sim devido às progênies de porta-enxerto de $C$. canephora (Apoatã 2258 e 2286) e a de C. congensis (Bangelan) (Tabela 5), em que as plantas pé-franco e enxertadas sobre elas mesmas, diferiram do portaenxerto. Na Tabela 6 ficou evidenciado que não houve diferença entre esses elementos, quando foram comparados os ramos com e sem sintoma de $X$. fastidiosa. FAHL et al. (1998) também observaram menores teores de manganês nas folhas dessas plantas enxertadas em análise realizada em 1988. Segundo Malavolta (1979), dentre as funções do manganês na planta estão as seguintes: ativação de diversas enzimas, participação no transporte eletrônico na fotossíntese, formação da clorofila e formação, funcionamento e multiplicação do cloroplasto. Já o cálcio faz parte da lamela média, ativa diversas enzimas e, também, desempenha outros papéis, tais como a regulação da permeabilidade da membrana plasmática, neutralização de ácidos tóxicos, desenvolvimento e funcionamento das raízes. 
Tabela 3. Média da proporção $(\mathrm{p})$ de obstrução de elementos de vaso do xilema pela bactéria X. fastidiosa em diferentes partes da planta a partir de ramos com e sem sintoma morfológico externo de cafeeiro no período seco (abril-maio) e período de chuvoso (novembro/dezembro) de 2000, na localidade de Garça (SP)

\begin{tabular}{|c|c|c|c|c|c|c|}
\hline \multirow{3}{*}{ Tratamento } & \multicolumn{3}{|c|}{ Período Seco } & \multicolumn{3}{|c|}{ Período chuvoso } \\
\hline & \multicolumn{2}{|c|}{ Folha } & \multirow[t]{2}{*}{ Caule } & \multicolumn{2}{|c|}{ Folha } & \multirow[t]{2}{*}{ Caule } \\
\hline & Limbo & Pecíolo & & Limbo & Pecíolo & \\
\hline & \multicolumn{6}{|c|}{ Ramo sem sintoma } \\
\hline Catuaí/Apoatã & 0,0135 & 0,0138 & 0,0189 & 0,0033 & 0,0077 & 0,0008 \\
\hline Catuaí/ Bangelan & 0,0292 & 0,0097 & 0,0164 & 0,0019 & 0,0026 & 0,0004 \\
\hline Catuaí/IAC 2286 & 0,0384 & 0,0272 & 0,0242 & 0,0047 & 0,0029 & 0,0014 \\
\hline Mundo Novo/Apoatã & 0,0035 & 0,0099 & 0,0073 & 0,0014 & 0,0016 & 0,0003 \\
\hline Mundo Novo/Bangelan & 0,0055 & 0,0272 & 0,0174 & 0,0055 & 0,0019 & 0,0000 \\
\hline Mundo Novo/IAC 2286 & 0,0095 & 0,0035 & 0,0100 & 0,0014 & 0,0005 & 0,0007 \\
\hline Catuaí/ Catuaí & 0,0014 & 0,0024 & 0,0055 & 0,0050 & 0,0036 & 0,0005 \\
\hline Mundo Novo/ Mundo Novo & 0,0032 & 0,0072 & 0,0032 & 0,0004 & 0,0000 & 0,0000 \\
\hline Mundo Novo (testemunha) & 0,0011 & 0,0070 & 0,0103 & 0,0032 & 0,0001 & 0,0039 \\
\hline \multirow[t]{2}{*}{ Catuaí (testemunha) } & 0,0053 & 0,0148 & 0,0105 & 0,0001 & 0,0002 & 0,0030 \\
\hline & \multicolumn{6}{|c|}{ Ramo com sintoma } \\
\hline Catuaí/Apoatã & 0,0512 & 0,0847 & 0,1194 & 0,0209 & 0,0259 & 0,0099 \\
\hline Catuaí/ Bangelan & 0,0600 & 0,1244 & 0,1279 & 0,0248 & 0,0334 & 0,0243 \\
\hline Catuaí/IAC 2286 & 0,0876 & 0,1361 & 0,1360 & 0,0334 & 0,0437 & 0,0205 \\
\hline Mundo Novo/Apoatã & 0,0359 & 0,0483 & 0,0874 & 0,0225 & 0,0421 & 0,0107 \\
\hline Mundo Novo/Bangelan & 0,0376 & 0,1205 & 0,1593 & 0,0220 & 0,0197 & 0,0182 \\
\hline Mundo Novo/IAC 2286 & 0,0464 & 0,1350 & 0,1706 & 0,0228 & 0,0398 & 0,0255 \\
\hline Catuaí/ Catuaí & 0,0363 & 0,1044 & 0,0818 & 0,0103 & 0,0384 & 0,0308 \\
\hline Mundo Novo/ Mundo Novo & 0,0666 & 0,0809 & 0,1007 & 0,0191 & 0,0314 & 0,0319 \\
\hline Mundo Novo (testemunha) & 0,0386 & 0,0782 & 0,0892 & 0,0121 & 0,0171 & 0,0271 \\
\hline Catuaí (testemunha) & 0,0475 & 0,0888 & 0,1314 & 0,0322 & 0,0336 & 0,0217 \\
\hline
\end{tabular}


Tabela 4. Limite inferior $\left(\mathrm{L}_{1}\right)$ e superior $\left(\mathrm{L}_{2}\right)$ da obstrução de elementos de vaso do xilema pela bactéria X. fastidiosa em diferentes partes da planta a partir de ramos, com e sem sintoma morfológico externo, de cafeeiros amostrados no período seco (abril-maio) e período chuvoso (novembro/dezembro) de 2000 na localidade de Garça (SP)

\begin{tabular}{|c|c|c|c|c|c|c|c|c|c|c|c|c|}
\hline \multirow{4}{*}{ Tratamento } & \multicolumn{6}{|c|}{ Período Seco (Estresse hídrico) } & \multicolumn{6}{|c|}{ Período Chuvoso } \\
\hline & \multicolumn{4}{|c|}{ Folha } & \multicolumn{2}{|c|}{ Caule } & \multicolumn{4}{|c|}{ Folha } & \multicolumn{2}{|c|}{ Caule } \\
\hline & \multicolumn{2}{|c|}{ Limbo } & \multicolumn{2}{|c|}{ Pecíolo } & \multirow[b]{2}{*}{$\mathrm{L}_{1}$} & \multirow[b]{2}{*}{$\mathrm{L}_{2}$} & \multicolumn{2}{|c|}{ Limbo } & \multicolumn{2}{|c|}{ Pecíolo } & \multirow[b]{2}{*}{$\mathrm{L}_{1}$} & \multirow[b]{2}{*}{$\mathrm{L}_{2}$} \\
\hline & $\mathrm{L}_{1}$ & $\mathrm{~L}_{2}$ & $\mathrm{~L}_{1}$ & $\mathrm{~L}_{2}$ & & & $\mathrm{~L}_{1}$ & $\mathrm{~L}_{2}$ & $\mathrm{~L}_{1}$ & $\mathrm{~L}_{2}$ & & \\
\hline & \multicolumn{12}{|c|}{ Ramo sem sintoma } \\
\hline Catuaí/Apoatã & $-0,0050$ & 0,0320 & $-0,0049$ & 0,0324 & $-0,0029$ & 0,0407 & $-0,0059$ & 0,0124 & $-0,0063$ & 0,0217 & $-0,0036$ & 0,0051 \\
\hline Catuaí/ Bangelan & 0,0022 & 0,0561 & $-0,0060$ & 0,0253 & $-0,0039$ & 0,0368 & $-0,0051$ & 0,0088 & $-0,0055$ & 0,0106 & $-0,0029$ & 0,0037 \\
\hline Catuaí/IAC 2286 & 0,0077 & 0,0692 & 0,0012 & 0,0532 & $-0,0004$ & 0,0488 & $-0,0062$ & 0,0156 & $-0,0057$ & 0,0116 & $-0,0045$ & 0,0073 \\
\hline Mundo Novo/Apoatã & $-0,0059$ & 0,0129 & $-0,0059$ & 0,0258 & $-0,0063$ & 0,0209 & $-0,0046$ & 0,0074 & $-0,0048$ & 0,0080 & $-0,0024$ & 0,0030 \\
\hline Mundo Novo/Bangelan & $-0,0063$ & 0,0174 & 0,0011 & 0,0532 & $-0,0035$ & 0,0383 & $-0,0063$ & 0,0174 & $-0,0051$ & 0,0090 & 0,0000 & 0,0000 \\
\hline Mundo Novo/IAC 2286 & $-0,0060$ & 0,0251 & $-0,0060$ & 0,0130 & $-0,0059$ & 0,0259 & $-0,0046$ & 0,0074 & $-0,0030$ & 0,0040 & $-0,0035$ & 0,0049 \\
\hline Catuaí/ Catuaí & $-0,0046$ & 0,0074 & $-0,0054$ & 0,0103 & $-0,0063$ & 0,0173 & $-0,0063$ & 0,0163 & $-0,0060$ & 0,0131 & $-0,0032$ & 0,0042 \\
\hline Mundo Novo/ Mundo Novo & $-0,0058$ & 0,0121 & $-0,0063$ & 0,0207 & $-0,0059$ & 0,0123 & $-0,0028$ & 0,0035 & 0,0000 & 0,0000 & 0,0000 & 0,0000 \\
\hline Mundo Novo (testemunha) & $-0,0042$ & 0,0065 & $-0,0063$ & 0,0204 & $-0,0059$ & 0,0264 & $-0,0058$ & 0,0122 & $-0,0013$ & 0,0014 & $-0,0061$ & 0,0138 \\
\hline \multirow[t]{2}{*}{ Catuaí (testemunha) } & $-0,0063$ & 0,0169 & $-0,0045$ & 0,0340 & $-0,0058$ & 0,0268 & $-0,0016$ & 0,0018 & $-0,0020$ & 0,0023 & $-0,0058$ & 0,0118 \\
\hline & \multicolumn{12}{|c|}{ Ramo com sintoma } \\
\hline Catuaí/Apoatã IAC 2258 & $-0,0006$ & 0,0865 & 0,0401 & 0,1293 & 0,0675 & 0,1712 & $-0,0020$ & 0,0437 & 0,0005 & 0,0513 & $-0,0060$ & 0,0257 \\
\hline Catuaí/ Bangelan & 0,0066 & 0,0980 & 0,0716 & 0,1772 & 0,0745 & 0,1813 & $-0,0001$ & 0,0496 & 0,0046 & 0,0622 & $-0,0003$ & 0,0490 \\
\hline Catuaí/IAC 2286 & 0,0327 & 0,1328 & 0,0813 & 0,1910 & 0,0811 & 0,1909 & 0,0047 & 0,0622 & 0,0110 & 0,0764 & $-0,0022$ & 0,0431 \\
\hline Mundo Novo/Apoatã IAC 2258 & $-0,0093$ & 0,0657 & 0,0140 & 0,0826 & 0,0422 & 0,1325 & $-0,0012$ & 0,0462 & 0,0099 & 0,0742 & $-0,0058$ & 0,0271 \\
\hline Mundo Novo/Bangelan & $-0,0209$ & 0,0681 & 0,0684 & 0,1726 & 0,1007 & 0,2179 & $-0,0015$ & 0,0454 & $-0,0025$ & 0,0419 & $-0,0032$ & 0,0395 \\
\hline Mundo Novo/IAC 2286 & $-0,0138$ & 0,0801 & 0,0803 & 0,1897 & 0,1104 & 0,2308 & $-0,0011$ & 0,0466 & 0,0085 & 0,0710 & 0,0003 & 0,0508 \\
\hline Catuaí/ Catuaí & $-0,0076$ & 0,0662 & 0,0555 & 0,1533 & 0,0379 & 0,1256 & $-0,0059$ & 0,0265 & 0,0076 & 0,0692 & 0,0032 & 0,0585 \\
\hline Mundo Novo/ Mundo Novo & 0,0184 & 0,1065 & 0,0372 & 0,1245 & 0,0525 & 0,1488 & $-0,0028$ & 0,0409 & 0,0035 & 0,0592 & 0,0038 & 0,0600 \\
\hline Mundo Novo (testemunha) & $-0,0070$ & 0,0694 & 0,0352 & 0,1211 & 0,0436 & 0,1349 & $-0,0054$ & 0,0295 & $-0,0037$ & 0,0378 & 0,0011 & 0,0530 \\
\hline Catuaí (testemunha) & $-0,0066$ & 0,0815 & 0,0433 & 0,1343 & 0,0774 & 0,1855 & 0,0039 & 0,0604 & 0,0048 & 0,0624 & $-0,0016$ & 0,0450 \\
\hline
\end{tabular}


Tabela 5. Teor de nutrientes da massa seca da parte aérea de todos os ramos amostrados da planta e de ramos com e sem sintoma de presença da X. fastidiosa

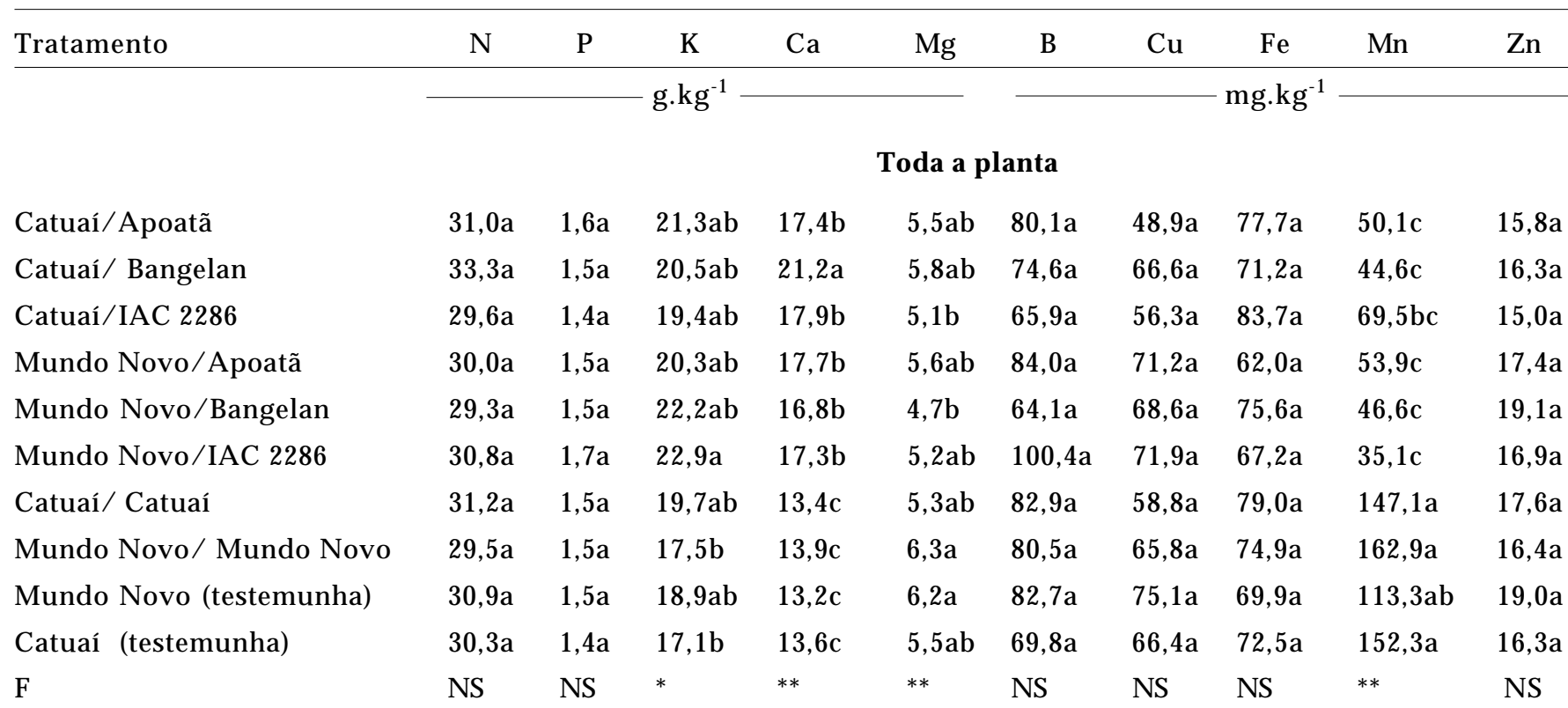

Catuaí/Apoatã
Catuaí/ Bangelan
Catuaí/IAC 2286
Mundo Novo/Apoatã
Mundo Novo/Bangelan
Mundo Novo/IAC 2286
Catuaí/ Catuaí
Mundo Novo/ Mundo Novo
Mundo Novo (testemunha)
Catuaí (testemunha)
F

Catuaí/Apoatã

Catuaí/ Bangelan

Catuaí/IAC 2286

Mundo Novo/Apoatã

Mundo Novo/Bangelan

Mundo Novo/IAC 2286

Catuaí/ Catuaí

Mundo Novo/ Mundo Novo

Mundo Novo (testemunha)

Catuaí (testemunha)

F

\section{Ramo com sintoma}

$\begin{array}{lll}30,6 a & 1,5 a & 19,5 a \\ 34,8 a & 1,4 a & 18,7 a \\ 26,6 a & 1,3 a & 17,0 a \\ 29,1 a & 1,4 a & 18,4 a \\ 28,3 a & 1,4 a & 21,1 a \\ 30,2 a & 1,5 a & 20,5 a \\ 30,2 a & 1,3 a & 17,1 a \\ 27,3 a & 1,3 a & 15,8 a \\ 29,9 a & 1,4 a & 17,9 a \\ 29,2 a & 1,2 a & 16,0 a \\ \text { NS } & \text { NS } & \text { NS }\end{array}$

$31,5 \mathrm{a} \quad 1,6 \mathrm{a} \quad 23,1 \mathrm{ab}$

$31,8 \mathrm{a} \quad 1,7 \mathrm{a} \quad 22,2 \mathrm{ab}$

$32,7 \mathrm{a} \quad 1,5 \mathrm{a} \quad 21,8 \mathrm{ab}$

$30,8 \mathrm{a} \quad 1,6 \mathrm{a} \quad 22,2 \mathrm{ab}$

$30,3 \mathrm{a} \quad 1,6 \mathrm{a} \quad 23,3 \mathrm{ab}$

$31,3 \mathrm{a} \quad 1,8 \mathrm{a} \quad 25,3 \mathrm{a}$

$32,2 \mathrm{a} \quad 1,6 \mathrm{a}$

$22,2 \mathrm{ab}$

$19,1 \mathrm{ab}$

$31,7 \mathrm{a} \quad 1,6 \mathrm{a}$

$31,8 \mathrm{a} \quad 1,6 \mathrm{a}$

$19,9 \mathrm{ab}$ 31,4a 1,5a 18,2b

$18,5 \mathrm{ab} \quad 5,7 \mathrm{a} \quad 76,2 \mathrm{a}$

$21,8 \mathrm{a}$

$5,7 a$

$57,7 \mathrm{a}$

$41,6 \mathrm{a}$

$61,4 \mathrm{a}$

$71,2 \mathrm{a}$

$63,8 a$

$19,5 \mathrm{ab}$

$17,5 \mathrm{ab}$

$15,4 \mathrm{bc}$

$17,4 \mathrm{ab}$

$13,6 \mathrm{bc}$

$13,6 b c$

$12,3 \mathrm{~cd}$

$13,9 b c$

**
$5,2 \mathrm{a}$

$51,6 \mathrm{a}$

$46,7 \mathrm{a}$

$61,0 \mathrm{a}$

$5,4 \mathrm{a}$

$83,1 \mathrm{a}$

$62,2 \mathrm{a}$

$63,0 \mathrm{a}$

$69,2 \mathrm{a}$

$52,9 a$

$59,1 \mathrm{a}$

$65,2 \mathrm{a}$

$63,4 \mathrm{a}$

$5,4 a$

NS
$5,0 \mathrm{a} \quad 96,5 \mathrm{a}$

$5,4 \mathrm{a} \quad 83,8 \mathrm{a}$

$71,7 a$

$79,0 \mathrm{a}$

$58,9 a$

NS
$60,0 b$

$17,5 \mathrm{a}$

$40,8 \mathrm{~b}$

$17,1 \mathrm{a}$

\section{Ramo sem sintoma}

$16,2 \mathrm{abc} \quad 5,2 \mathrm{a} \quad 83,9 \mathrm{a}$

$20,6 a \quad 6,0 a$

$91,4 \mathrm{a}$

$56,1 \mathrm{a}$

$84,2 a$

$40,2 \mathrm{c}$

$14,0 \mathrm{a}$

$16,4 \mathrm{abc} \quad 4,9 \mathrm{a}$

$80,1 \mathrm{a}$

$71,9 \mathrm{a}$

$78,6 \mathrm{a}$

$48,4 \mathrm{c}$

$15,4 \mathrm{a}$

$17,8 \mathrm{ab} \quad 5,8 \mathrm{a}$

$84,9 a$

$65,9 a$

$106,4 a$

$65,2 \mathrm{bc}$

$15,7 \mathrm{a}$

$18,1 \mathrm{ab} \quad 5,0 \mathrm{a}$

$78,1 \mathrm{a}$

80,2

$54,0 \mathrm{bc}$

$16,7 \mathrm{a}$

$17,1 \mathrm{abc} \quad 5,4 \mathrm{a}$

$104,3 a$

$74,2 \mathrm{a}$

$94,6 \mathrm{a}$

$51,6 \mathrm{bc}$

$17,3 \mathrm{a}$

$13,1 \mathrm{c} \quad 5,2 \mathrm{a}$

$82,1 \mathrm{a}$

$74,6 \mathrm{a}$

$76,8 \mathrm{a}$

$41,4 \mathrm{c}$

$15,9 \mathrm{a}$

$14,2 \mathrm{bc}$

$6,5 a$

$89,2 \mathrm{a}$

$64,8 \mathrm{a}$

$97,4 a$

$146,0 \mathrm{abc}$

$17,7 \mathrm{a}$

$14,1 \mathrm{bc}$

$6,3 a$

$86,3 a$

$72,5 \mathrm{a}$

$88,4 \mathrm{a}$

$157,4 \mathrm{ab}$

$15,3 a$

$13,4 \mathrm{~cd}$

$5,7 a$

$80,6 \mathrm{a}$

$118,2 \mathrm{bc}$

$18,0 \mathrm{a}$

** NS NS

NS NS $167,4^{\mathrm{a}} \quad 15,6 \mathrm{a}$

** NS

Médias seguidas pela mesma letra na vertical não diferem entre si pelo teste de Tukey a 5\%. NS: não significativo; *,**: significativo a $5 \%$ e a $1 \%$ pelo teste $\mathrm{F}$ respectivamente. 
Tabela 6. Comparação entre os teores de nutrientes da massa seca da parte aérea de cultivares de cafeeiro obtidos a partir de ramos com (1) e sem sintoma (2) da presença da X. fastidiosa

\begin{tabular}{|c|c|c|c|c|c|c|c|c|c|c|c|}
\hline Tratamentos & Sintomas & $\mathrm{N}$ & $\mathrm{P}$ & K & $\mathrm{Ca}$ & $\mathrm{Mg}$ & B & $\mathrm{Cu}$ & $\mathrm{Fe}$ & Mn & $\mathrm{Zn}$ \\
\hline & & & . & g.kg- & & 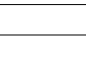 & 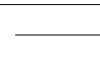 & 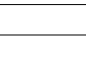 & mg.kg-1 & & \\
\hline & 1 & 30,6 & 1,5 & 19,5 & 18,5 & 5,7 & 76,2 & 41,6 & 71,2 & 60,0 & 17,5 \\
\hline \multirow[t]{3}{*}{ Catuaí/Apoatã } & 2 & 31,5 & 1,6 & 23,1 & 16,2 & 5,2 & 83,9 & 56,1 & 84,2 & 40,2 & 14,0 \\
\hline & $\mathrm{F}$ & NS & NS & NS & NS & NS & NS & NS & NS & NS & NS \\
\hline & 1 & 34,8 & 1,4 & 18,9 & 21,8 & 5,7 & 57,7 & 61,4 & 63,8 & 40,8 & 17,1 \\
\hline \multirow[t]{3}{*}{ Catuaí/ Bangelan } & 2 & 31,8 & 1,7 & 22,2 & 20,6 & 6,0 & 91,4 & 71,9 & 78,6 & 48,4 & 15,4 \\
\hline & $\mathrm{F}$ & NS & NS & NS & NS & NS & NS & NS & $* *$ & NS & NS \\
\hline & 1 & 26,6 & 1,3 & 17,0 & 19,5 & 5,2 & 51,6 & 46,7 & 61,0 & 73,8 & 14,3 \\
\hline \multirow[t]{3}{*}{ Catuaí/IAC 2286} & 2 & 32,7 & 1,5 & 21,8 & 16,4 & 4,9 & 80,2 & 65,9 & 106,4 & 65,2 & 15,7 \\
\hline & $\mathrm{F}$ & NS & NS & NS & NS & NS & NS & $* *$ & NS & NS & NS \\
\hline & 1 & 29,1 & 1,4 & 18,4 & 17,5 & 5,4 & 83,1 & 62,2 & 56,6 & 53,8 & 18,2 \\
\hline \multirow[t]{3}{*}{ Mundo Novo/Apoatã } & 2 & 30,8 & 1,6 & 22,2 & 17,8 & 5,8 & 84,9 & 80,2 & 67,4 & 54,0 & 16,7 \\
\hline & $\mathrm{F}$ & NS & NS & NS & NS & NS & NS & NS & NS & NS & NS \\
\hline & 1 & 28,3 & 1,4 & 21,1 & 15,4 & 4,4 & 50,2 & 63,0 & 56,6 & 41,6 & 20,9 \\
\hline \multirow{3}{*}{ Mundo Novo/Bangelan } & 2 & 30,3 & 1,6 & 23,3 & 18,1 & 5,0 & 78,1 & 74,2 & 94,6 & 51,6 & 17,3 \\
\hline & $\mathrm{F}$ & NS & NS & NS & NS & NS & NS & NS & * & NS & NS \\
\hline & 1 & 30,2 & 1,5 & 20,5 & 17,4 & 5,0 & 96,5 & 69,2 & 57,6 & 28,8 & 18,0 \\
\hline \multirow[t]{3}{*}{ Mundo Novo/IAC 2286} & 2 & 31,3 & 1,8 & 25,3 & 17,1 & 5,4 & 104,3 & 74,6 & 76,8 & 41,4 & 15,9 \\
\hline & $\mathrm{F}$ & NS & NS & NS & NS & NS & NS & NS & NS & NS & NS \\
\hline & 1 & 30,2 & 1,3 & 17,1 & 13,6 & 5,4 & 83,8 & 52,9 & 60,6 & 148,2 & 17,4 \\
\hline \multirow[t]{3}{*}{ Catuaí/ Catuaí } & 2 & 32,2 & 1,6 & 22,2 & 13,1 & 5,2 & 82,1 & 64,8 & 97,4 & 146,0 & 17,7 \\
\hline & $\mathrm{F}$ & NS & $*$ & NS & NS & NS & NS & NS & NS & NS & NS \\
\hline & 1 & 27,3 & 1,3 & 15,8 & 13,6 & 6,1 & 71,7 & 59,1 & 61,4 & 168,4 & 17,6 \\
\hline Mundo Novo/Mundo & 2 & 31,7 & 1,6 & 19,1 & 14,2 & 6,5 & 89,2 & 72,5 & 88,4 & 157,4 & 15,3 \\
\hline \multirow[t]{2}{*}{ Novo } & $\mathrm{F}$ & NS & $* *$ & NS & NS & NS & NS & NS & * & NS & NS \\
\hline & 1 & 29,9 & 1,4 & 17,9 & 12,3 & 6,0 & 79,0 & 65,2 & 65,2 & 108,4 & 20,1 \\
\hline Mundo Novo & 2 & 31,8 & 1,6 & 19,9 & 14,1 & 6,3 & 86,3 & 85,0 & 74,6 & 118,2 & 18,0 \\
\hline \multirow[t]{2}{*}{ (testemunha) } & F & * & NS & NS & NS & NS & NS & NS & NS & NS & NS \\
\hline & 1 & 29,2 & 1,2 & 16,0 & 13,9 & 5,4 & 58,9 & 63,4 & 73,0 & 137,2 & 17,0 \\
\hline \multirow[t]{2}{*}{ Catuaí (testemunha) } & 2 & 31,4 & 1,5 & 18,2 & 13,4 & 5,7 & 80,6 & 69,4 & 72,0 & 167,4 & 15,6 \\
\hline & F & * & NS & NS & NS & NS & NS & NS & NS & NS & NS \\
\hline
\end{tabular}

Médias seguidas pela mesma letra na vertical não diferem entre si pelo teste de Tukey a 5\%. NS: não significativo;

*,**: significativo a $5 \%$ e $1 \%$ pelo teste $\mathrm{F}$ respectivamente. 
O cálcio é o macronutriente mais imóvel da planta; seu deslocamento é unidirecional, das raízes até as zonas meristemáticas e tecido jovem; quando em excesso nos tecidos, acumula-se na forma de oxalato de cálcio (HANGER, 1979).

Os tratamentos porta-enxertados poderiam apresentar uma vantagem em relação ao pé-franco quanto à eficiência na absorção de cálcio, porém, foram menos adaptados na absorção de manganês. Quanto à obstrução de elementos de vaso pela bactéria, não houve diferença significativa entre os tratamentos.

Neste trabalho, a presença da X. fastidiosa na cultura ocasionou o sintoma externo e a obstrução dos elementos de vaso do xilema até o nível de $7 \%$ no pecíolo e caule na época de seca, mas não ocorreu nas folhas o desequilíbrio nutricional esperado, como menores concentrações de zinco, as quais promovem os sintomas externos típicos da presença da bactéria. Estudos de acompanhamento do balanço nutricional das plantas e da doença serão realizados futuramente a fim de compreender o efeito da bactéria no cafeeiro.

Comparando-se o estado nutricional de ramos, com e sem sintoma da presença da X. fastidiosa (Tabela 6), observou-se que houve diminuição nos teores de ferro em 'Catuaí' e 'Mundo Novo' porta-enxertada sobre Bangelan e 'Mundo Novo' enxertada sobre ela mesma; de fósforo em 'Catuaí' e 'Mundo Novo' enxertadas sobre elas mesmas e no teor de cobre nos ramos com sintoma da bactéria, em Catuaí enxertada sobre IAC 2286, embora dentro dos teores adequados para o cafeeiro.

A enxertia é uma técnica que tem sido utilizada com sucesso para substituir o sistema radicular de cultivares de C. arabica, suscetíveis ao ataque de fungos, nematóides e outros patógenos das raízes. A utilização de linhagens de C. canephora, tolerantes a nematóides como porta-enxerto para cultivares de C. arabica, aumenta consideravelmente a produção das plantas enxertadas estabelecidas em solos infestados por esses patógenos (FAzUoli et al.,1983). Nenhum dos materiais genéticos estudados apresentou-se promissor em relação à resistência à bactéria X. fastidiosa, exceto Mundo Novo enxertada sobre a Apoatã, que mostrou tendência de possuir menor proporção de obstrução de elementos de vaso ocasionado pela ação da bactéria.

$\mathrm{O}$ resultado da análise de solo revelou o seguinte resultado: $\mathrm{MO}-6$ g.dm ${ }^{-3} ; \mathrm{pH} \mathrm{em} \mathrm{CaCl}_{2}-4,5$; P resina $-37 \mathrm{mg} \cdot \mathrm{dm}^{-3}$; teores trocáveis, em $\mathrm{mmol}_{\mathrm{c}} \cdot \mathrm{dm}^{-3}$ : $\mathrm{K}-1,6 ; \mathrm{Ca}-13 ; \mathrm{Mg}-4 ; \mathrm{H}+\mathrm{Al}-28$ e V $-40 \%$. Os teores de boro, cobre, ferro, manganês e zinco foram respectivamente em $\mathrm{mg} \cdot \mathrm{dm}^{-3}: 0,46 ; 5,7,66,0 ; 2,8$ e 0,8 .
A água parece ser o fator limitante na expressão do sintoma externo e de obstrução dos vasos do xilema pela $X$. fastidiosa. O fator temperatura parece não interferir. PURCELl (1980) descartou a hipótese de que a baixa temperatura seria uma condição ótima para diminuir o efeito da bactéria, pois observou que era um efeito indireto ocasionado pela diminuição da absorção hídrica. No entanto, neste trabalho, o "período" de baixas temperaturas e pluviosidade foram responsáveis por um aumento da obstrução de elementos de vasos do xilema nas partes estudadas da planta.

A interação "Xylella - planta - vetor" é complexa e são necessários, ainda, muitos estudos para a compreensão dessa relação.

\section{CONCLUSÕES}

1. A proporção de obstrução de elementos de vaso do xilema, devido ao efeito de infecção pela bactéria Xylella fastidiosa, é maior no período seco do ano que causa estresse hídrico (maio-junho) do que no chuvoso, sem esse estresse (novembro-dezembro);

2. O órgão que apresentou uma proporção maior de obstrução de elementos de vaso foi o caule seguido do pecíolo, limbo e raiz;

3. Não houve diferença significativa na proporção de elementos de vaso obstruídos entre 'Catuaí' e 'Mundo Novo', enxertados ou pé-franco, amostrados nos dois períodos do ano;

4. A presença da X. fastidiosa na planta não alterou a composição ótima nutricional foliar, porém as folhas retiradas dos ramos com sintoma da bactéria de Catuaí e Mundo Novo enxertada sobre ela mesma apresentaram teores mais baixos do fósforo em relação àquelas retiradas de ramos sem sintoma da doença;

5. O teor do micronutriente cobre também foi menor nas folhas de ramos com sintoma de Catuaí enxertada sobre IAC 2286; o ferro foi menor em Catuaí e no Mundo Novo porta-enxertada sobre Bangelan e em Mundo Novo enxertada sobre ela mesma.

\section{AGRADECIMENTOS}

Ao Pesquisador Científico do IAC, Armando Conagin, pela orientação nas análises estatísticas. Ao proprietário da Fazenda da Mata, Sr. Nino Bonini, e aos Engenheiros Agrônomos da GARCAFÉ, Gustavo Guerreiro e José Antônio de Mendonça Otoboni pelo manejo da cultura. 


\section{REFERÊNCIAS}

BATAGLIA, O.C.; FURLANI, A.M.C.; TEIXEIRA, J.P.F.; FURLANI, P.R.0.; GALLO, J.R. Métodos de análise química de plantas. Campinas: Instituto Agronômico, 1983. 48p. (Boletim técnico, 78).

CHAGAS, C.M.; ROSSETTI, V.; BERETTA, M.J.G. Electron microscopy studies of xylem-limited bacterium in sweetorange affected with Citrus variegated chlorosis disease in Brazil. Journal of Phytopathology, Berlin, v.34, p.306-312, 1992.

ESAU, K. Anatomic effects of the viruses of pierce's disease and phony peach. Hilgardia, Berkeley, v.18, n.12, p.423-482, 1948.

EVERT, D.R.; MULLINIX Jr., B.G. Xylem water potential of peach trees infected with phony disease. HortScience, Alexandria, v.18, p.719-721, 1983.

FAHL, J.I.; CARELLI, M.L.C.; GALLO, P.B.; COSTA, W.M.; NOVO, M.C.S.S. Enxertia de Coffea arabica sobre progênies de C. canephora e de $C$. congensis no crescimento, nutrição mineral e produção. Bragantia, Campinas, v.57, n.2, p.297-312, 1998.

FAZUOLI, L.C.; COSTA, W.M.; BORTOLETTO, N. Efeitos do porta-enxerto IAC 2258 de Coffea canephora, resistente a Meloidogyne incognita, no desenvolvimento e produção iniciais de dois cultivares de Coffea arabica. In: CONGRESSO BRASILEIRO DE PESQUISAS CAFEEIRAS, 10, Poços de Caldas, 1983. Anais... Rio de Janeiro, MIC/IBC, 1983. p.113-115.

FRENCH, W.J.; STASSI, D.L. Response of phony-infected peach trees to gibberellic acid. HortScience, Alexandria, v.13, n.2, p.158-159, 1978.

FRY, S.M.; MILHOLLAND, R.D. Multiplication and translocation of Xylella fastidiosa in petioles and stems of grapevine resistant, tolerant, and susceptible to Pierce's disease. Phytopathology, St. Paul, v.80, n.1, p.61-65, 1990.

GABRIELLI, A.C. Contribuição ao estudo anatômico da raiz de Pyrostegia venusta (Ker) Miers-Bignoniaceae. Revista Brasileira de Botânica, São Paulo, v.15, n.2, p.95-104, 1992.

GOHEEN, A.C.; NYLAND, G.; LOWE, S.K. Association of a rickettsia-like organism with Pierce's disease of grapevines and alfalfa dwarf and heat therapy of the disease in grapevines. Phytopathology, St. Paul, v.63, p.341-345, 1973.

HANGER, B.C. The movement of calcium in plants. Communication in Soil Science and Plant Analysis. v.10, p.171193, 1979.

HOPKINS, D.L. Seasonal concentration of the Pierce's disease bacterium in grapevine stems, petioles and leaf veins. Phytopathology, St. Paul, v.71, p.415-418, 1981.

HOPKINS, D.L. Seasonal fluctuation in the occurrence of Xylella fastidiosa in root and stem extracts from Citrus with blight. Plant Disease, St. Paul, v.75, n.2, p.145-147, 1991.
HOPKINS, D.L. Xylella fastidiosa: xylem-limited bacterial pathogen of plants. Annual Review Phytopathology, Palo Alto, v.27, p.271-290, 1989.

HOPKINS, D.L.; ADLERZ, W.C. Natural hosts of Xylella fastidiosa in Florida. Plant Disease, St. Paul, v.72, p.429-431, 1988.

HOPKINS, D.L.; MOLLENHAUER, H.A.; FRENCH, W.J. Occurrence of a rickettsia-like bacterium in the xylem of peach trees with phony disease. Phytopathology, St. Paul, v.63, p.1422-1423, 1973.

HOPKINS, D.L.; THOMPSON, C.M. Seasonal concentration of the Pierce's disease bacterium in "Carlos" and "Welder" muscadine grapes compared with 'Schuyler' bunch grape. HortScience, Alexandria, v.19, p.419-420, 1984.

JOHANSEN, D.A. Plant microtechnique. New York, McGrawHill, 1940. 523p.

LEE, R.F.; RAJU, B.C.; NYLAND, G.; GOHEEN, A. C. Phytotoxin (s) produced in culture by the Pierce's disease bacterium. Phytopathology, St. Paul, v.72, p.886-888, 1982.

LOPES, J.R.S. Mecanismos de transmissão de Xylella fastidiosa por cigarrinhas. Laranja, Cordeirópolis, v.17, n.1, p.79-92, 1996.

MALAVOLTA, E. Nutrição mineral. In: FERRI, M.G. (Ed.) Fisiologia Vegetal. São Paulo: EDUSP, 1979. v.1. p.97-113.

MIRCETICH, S.M.; LOWE, S.K.; MOLLER, W.J.; NYLAND, G. Etiology of almond leaf scorch disease and transmission of the causal agent. Phytopathology, St. Paul, v.66, p.17-24, 1976.

MOLLENHAUER, H.A.; HOPKINS, D.L. Xylem morphology of Pierce's disease-infected grapevines with different levels of tolerance. Physiological Plant Pathology, New York, v.9, p.95-100, 1976.

NYLAND, G.; GOHEEN, A.C.; LOWE, S.K.; KIRKPATRICK, H.C. The ultrastructure of a rickettsia-like organism from a peach tree affected with phony disease. Phytopathology, St. Paul, v.63, p.1255-1258, 1973.

OLIVEIRA, A.C.; VALLIM, M.A. Quantification of Xylella fastidiosa from Citrus trees by real-time polymerase chain reaction assay. Phytopathology, St. Paul, v.92, n.10, p.10481054, 2002.

PAIVA, P.E.B.; SILVA, J.L.; GRAVENA, S.; YAMAMOTO, P.T. Cigarrinhas de xilema em pomares de laranja do Estado de São Paulo. Laranja, Cordeirópolis, v.17, n.1, p.41-54, 1996.

PARADELA FILHO, O.; SUGIMORI, M.H.; RIBEIRO, I.J.A.; GARCIA JUNIOR., A.; BERETTA, M.J.G.; HARAKAWA, R.; MACHADO, M.A.; LARANJEIRA, F.F.; RODRIGUES NETO, J.; BERIAM, L.O.S. Primeira constatação em cafeeiro no Brasil da Xylella fastidiosa causadora da clorose variegada dos citros. Laranja, Cordeirópolis, v.16, n.2, p.135-136, 1995.

PARADELA FILHO, O.; SUGIMORI, M.H.; RIBEIRO, I.J.A.; GARCIA Jr., A.; BERETTA, M.J.G.; HARAKAWA, R.; MACHADO, M.A.; LARANJEIRA, F.F.; RODRIGUES NETO, J.; BERIAM, L.O.S. Constatação de Xylella fastidiosa em cafeeiro no Brasil. Summa Phytopathologica, Jaboticabal, v.23, p.46-49, 1997. 
PARADELA FILHO, O.; THOMAZIELLO, R.A.; BERETTA, M.J.G.; FAZUOLI, L.C.; OLIVEIRA, E.G. de; FAHL, J.I.; PEZZOPANE, J.R. M. Atrofia dos ramos de cafeeiro, causada por Xylella fastidiosa. Campinas: Instituto Agronômico, 1999. 10p. (Boletim Técnico, 182)

PRATO, J.R.A. Quem diria, a Xylella fastidiosa sempre esteve no café. A Granja, fevereiro/2000, n. 614, p.40-43, 2000.

PURCELL, A.H. Environmental therapy for Pierce's disease of grapevines. Plant Disease, St. Paul, v.64, n.4, p.388-390, 1980.

QUEIROZ-VOLTAN, R.B.; PARADELA FILHO,O.; CARELLI, M.L.C.; FAHL, J.I. Aspectos estruturais de cafeeiro infectado com Xylella fastidiosa. Bragantia, Campinas, v.57, n.1, p.23-33, 1998.
RAIJ, B. van; CANTARELLA, H.; QUAGGIO, J.A. Estimulantes. In: RAIJ, B.van; CANTARELLA, H.; QUAGGIO, J.A.; FURLANI, A.M.C. (Eds.). Recomendações de adubação e calagem para o Estado de São Paulo. 2. ed. Campinas, Instituto Agronômico \& Fundação IAC, 1997. 285p. (Boletim técnico, 100).

SOKAL, R.R.; ROHLF, F.J. Biometry. 2.ed. New York: W.F. Freeman, 1981. 859p. 